\section{Completed Learning Demonstration Composite Data Products as of December 1, 2006}

Technical Report NREL/TP-560-41090 February 2007

Keith Wipke 
This report was prepared as an account of work sponsored by an agency of the United States government. Neither the United States government nor any agency thereof, nor any of their employees, makes any warranty, express or implied, or assumes any legal liability or responsibility for the accuracy, completeness, or usefulness of any information, apparatus, product, or process disclosed, or represents that its use would not infringe privately owned rights. Reference herein to any specific commercial product, process, or service by trade name, trademark, manufacturer, or otherwise does not necessarily constitute or imply its endorsement, recommendation, or favoring by the United States government or any agency thereof. The views and opinions of authors expressed herein do not necessarily state or reflect those of the United States government or any agency thereof.

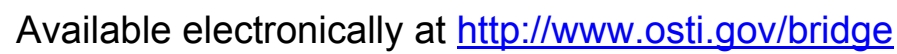

Available for a processing fee to U.S. Department of Energy and its contractors, in paper, from:

U.S. Department of Energy

Office of Scientific and Technical Information

P.O. Box 62

Oak Ridge, TN 37831-0062

phone: 865.576 .8401

fax: 865.576 .5728

email: mailto:reports@adonis.osti.gov

Available for sale to the public, in paper, from:

U.S. Department of Commerce

National Technical Information Service

5285 Port Royal Road

Springfield, VA 22161

phone: 800.553 .6847

fax: 703.605 .6900

email: orders@ntis.fedworld.gov

online ordering: http://www.ntis.gov/ordering.htm

Printed on paper containing at least $50 \%$ wastepaper, including $20 \%$ postconsumer waste 


\section{Completed Learning Demonstration Composite Data Products as of $12 / 01 / 06$}

Prepared under Task No. H270.8100 


\section{CDP\#1A: Learning Demo Fuel Cell Stack Hours Accumulated Through August 2006}

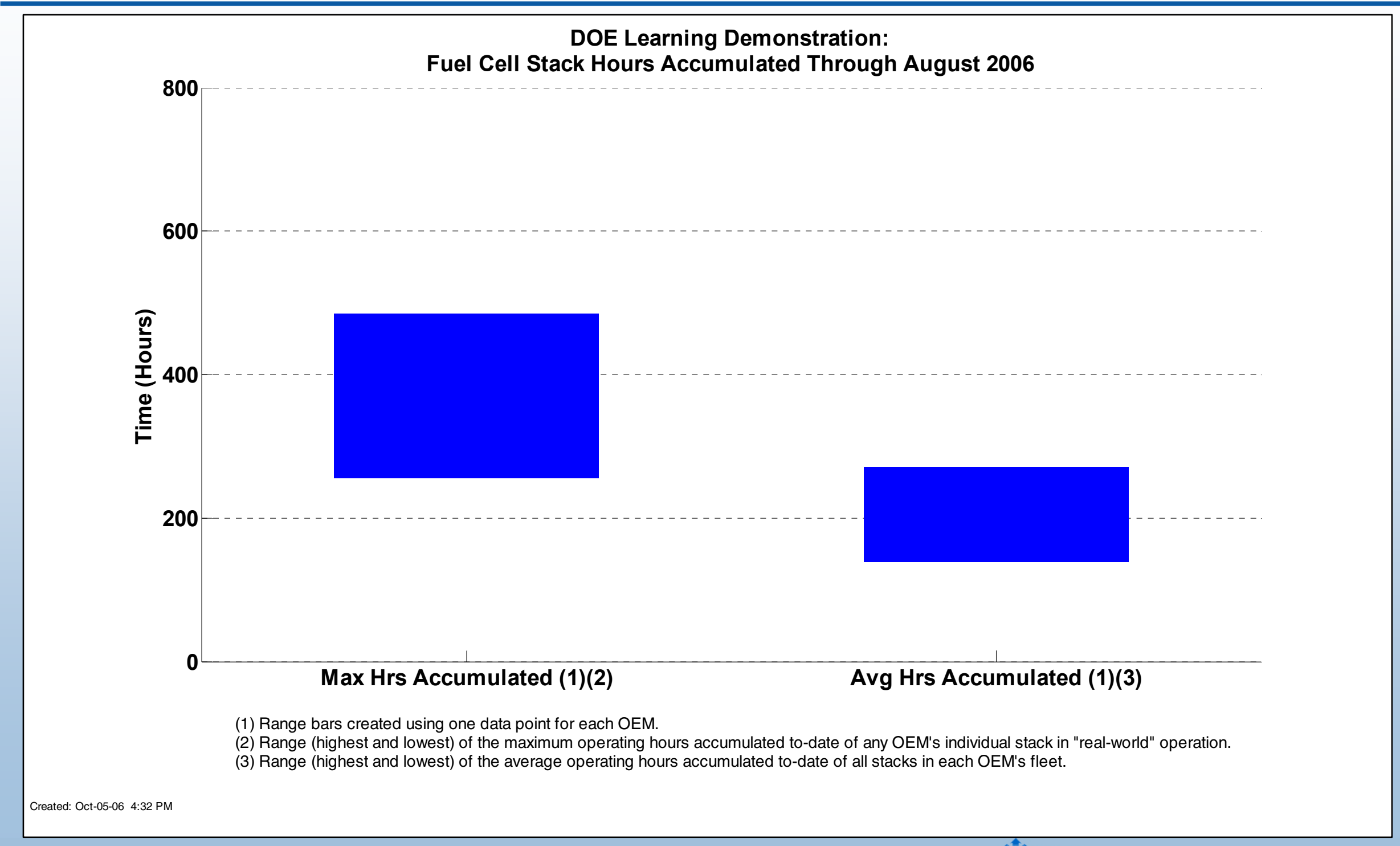




\section{CDP\#1B: Projected Hours to $10 \%$ Stack Voltage Degradation}

DOE Learning Demonstration Fuel Cell Stack Durability: Based on Data Through August 2006

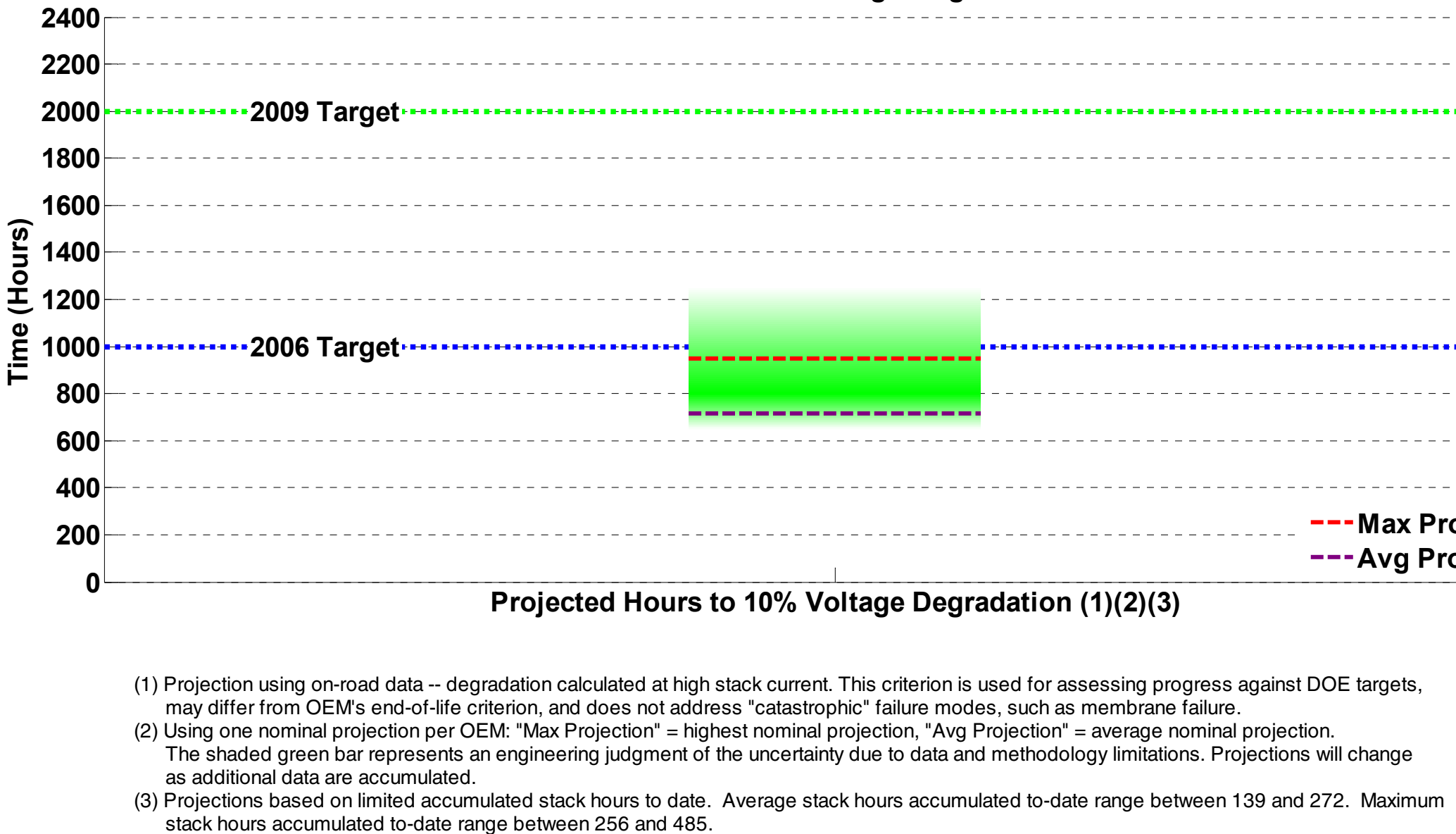




\section{CDP\#1C: Hours Accumulated and}

\section{Projected Hours to $10 \%$ Stack Voltage Degradation}

DOE Learning Demonstration Fuel Cell Stack Durability:

Based on Data Through August 2006

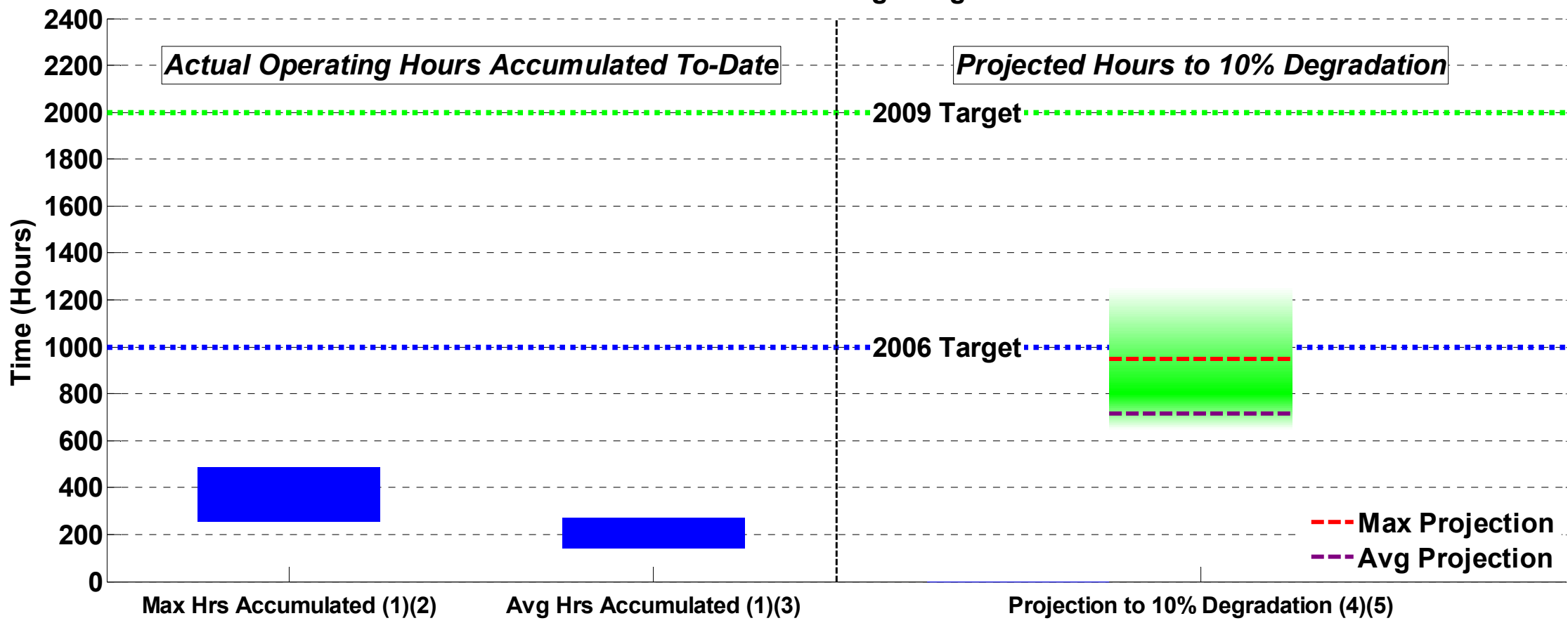

(1) Range bars created using one data point for each OEM.

(2) Range (highest and lowest) of the maximum operating hours accumulated to-date of any OEM's individual stack in "real-world" operation.

(3) Range (highest and lowest) of the average operating hours accumulated to-date of all stacks in each OEM's fleet.

(4) Projection using on-road data -- degradation calculated at high stack current. This criterion is used for assessing progress against DOE targets, may differ from OEM's end-of-life criterion, and does not address "catastrophic" failure modes, such as membrane failure.

(5) Using one nominal projection per OEM: "Max Projection" = highest nominal projection, "Avg Projection" = average nominal projection.

The shaded green bar represents an engineering judgment of the uncertainty due to data and methodology limitations. Projections will change as additional data are accumulated. 


\section{CDP\#2: Vehicle Range}

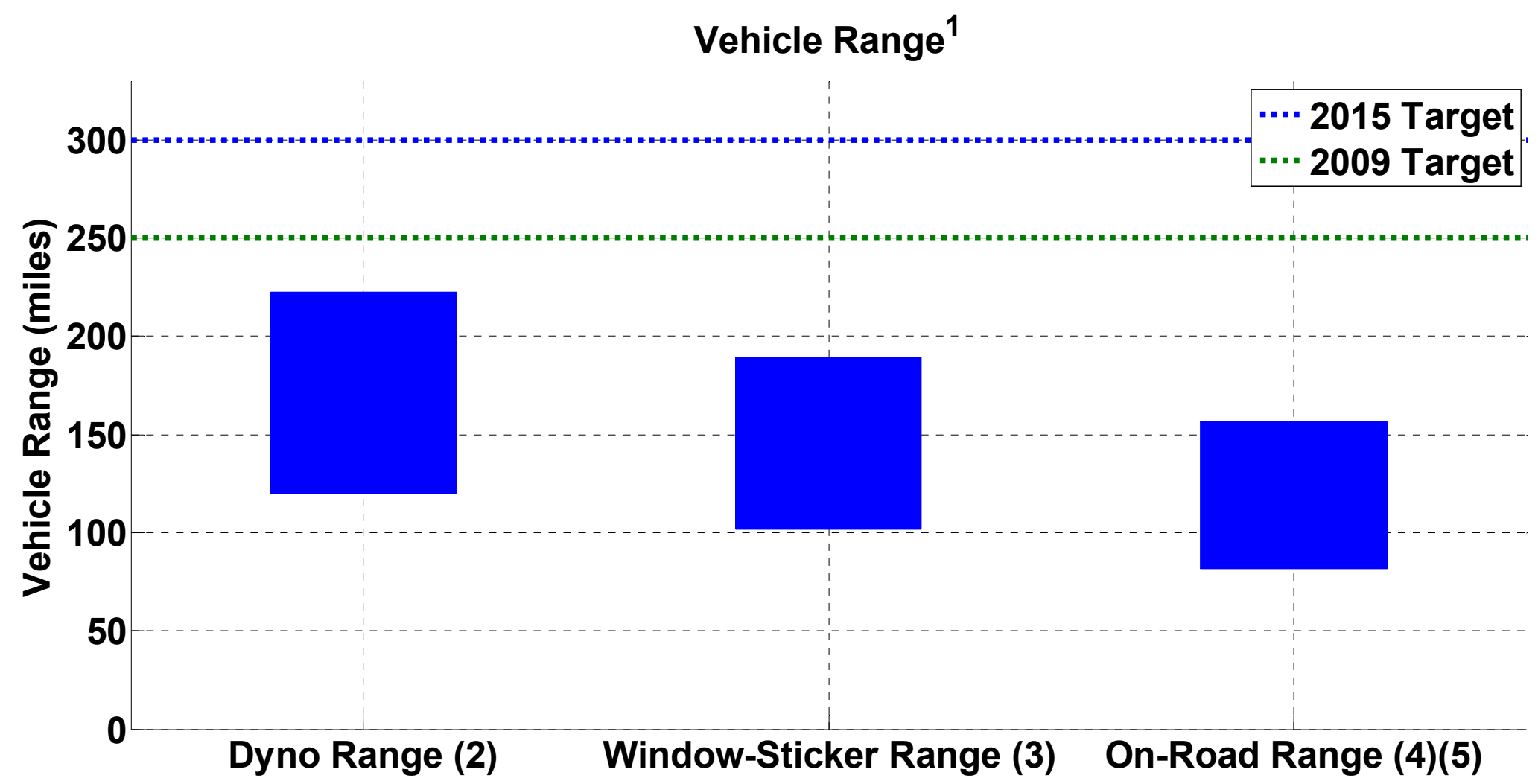

(1) Range is based on fuel economy and usable hydrogen on-board the vehicle. One data point for each make/model.

(2) Fuel economy from unadjusted combined City/Hwy per DRAFT SAEJ2572.

(3) Fuel economy from EPA Adjusted combined City/Hwy (0.78 x Hwy, 0.9 x City).

(4) Excludes trips $<1$ mile. One data point for on-road fleet average of each make/model.

(5) Fuel economy calculated from on-road fuel cell stack current or mass flow readings. 


\section{CDP\#6: Fuel Economy}

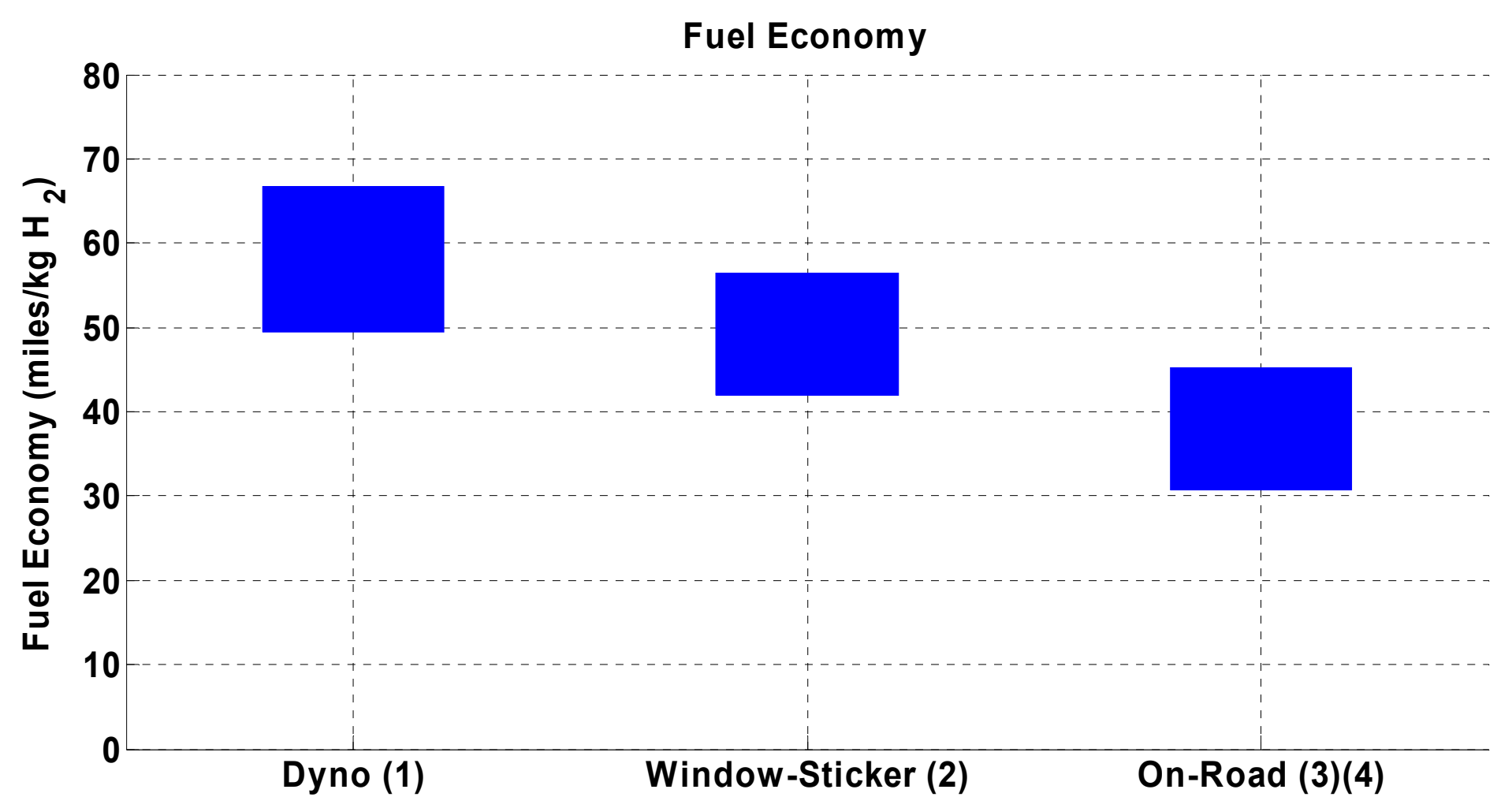

(1) One data point for each make/model. Combined City/Hwy fuel economy per DRAFT SAEJ2572.

(2) Adjusted combined City/Hwy fuel economy (0.78 x Hwy, 0.9 x City).

(3) Excludes trips < 1 mile. One data point for on-road fleet average of each make/model.

Created: Aug-25-06 10:45 AM (4) Calculated from on-road fuel cell stack current or mass flow readings. 


\section{CDP\#8: FC System Efficiency}

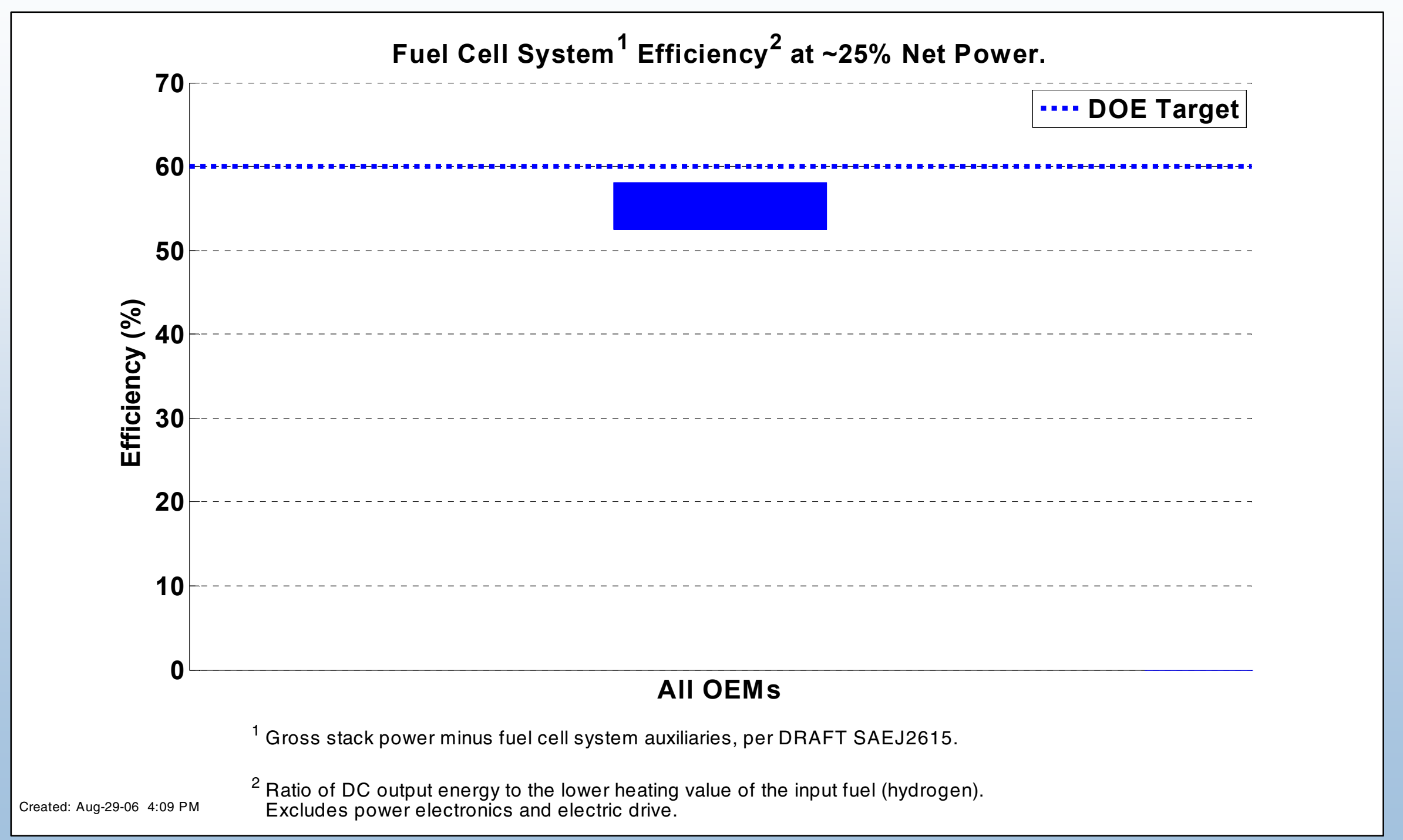




\section{CDP\#9: Safety Incidents - Vehicles}

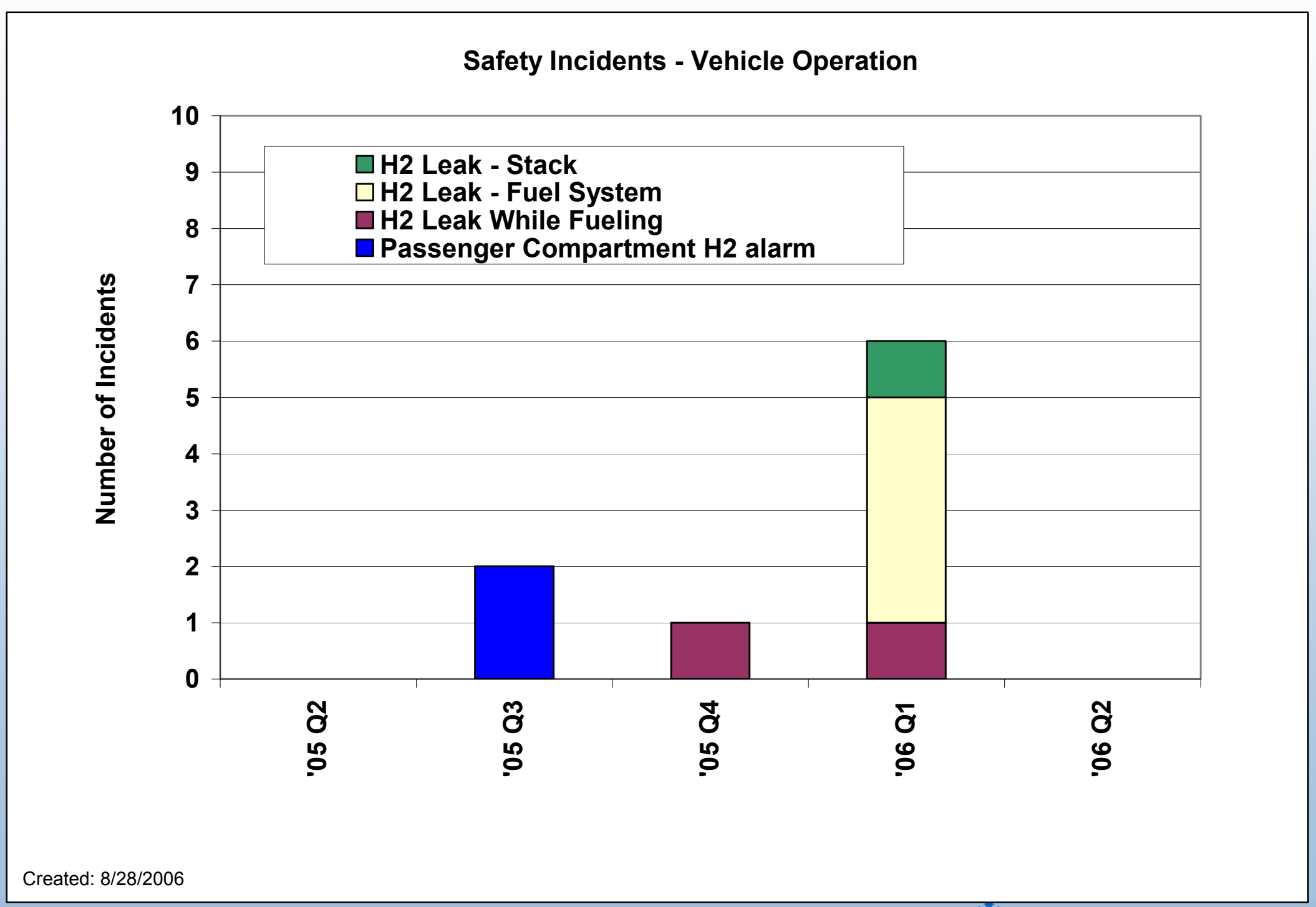




\section{CDP\#10: Storage Weight \% Hydrogen}

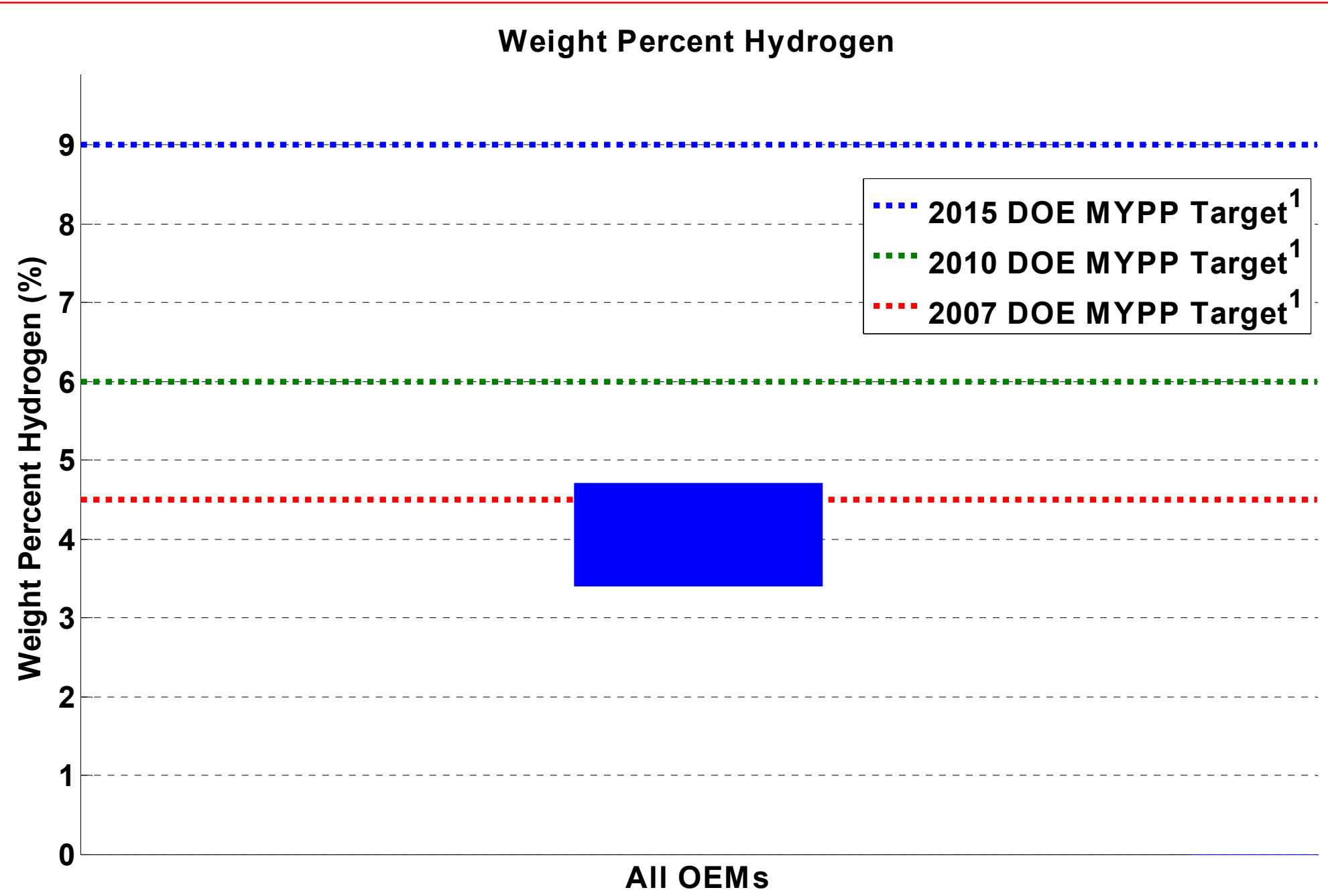

${ }^{1}$ Some near-term targets have been achieved with compressed and liquid tanks. Emphasis is on advanced materials-based technologies. 


\section{CDP\#11: Volumetric Capacity of H2 Storage}

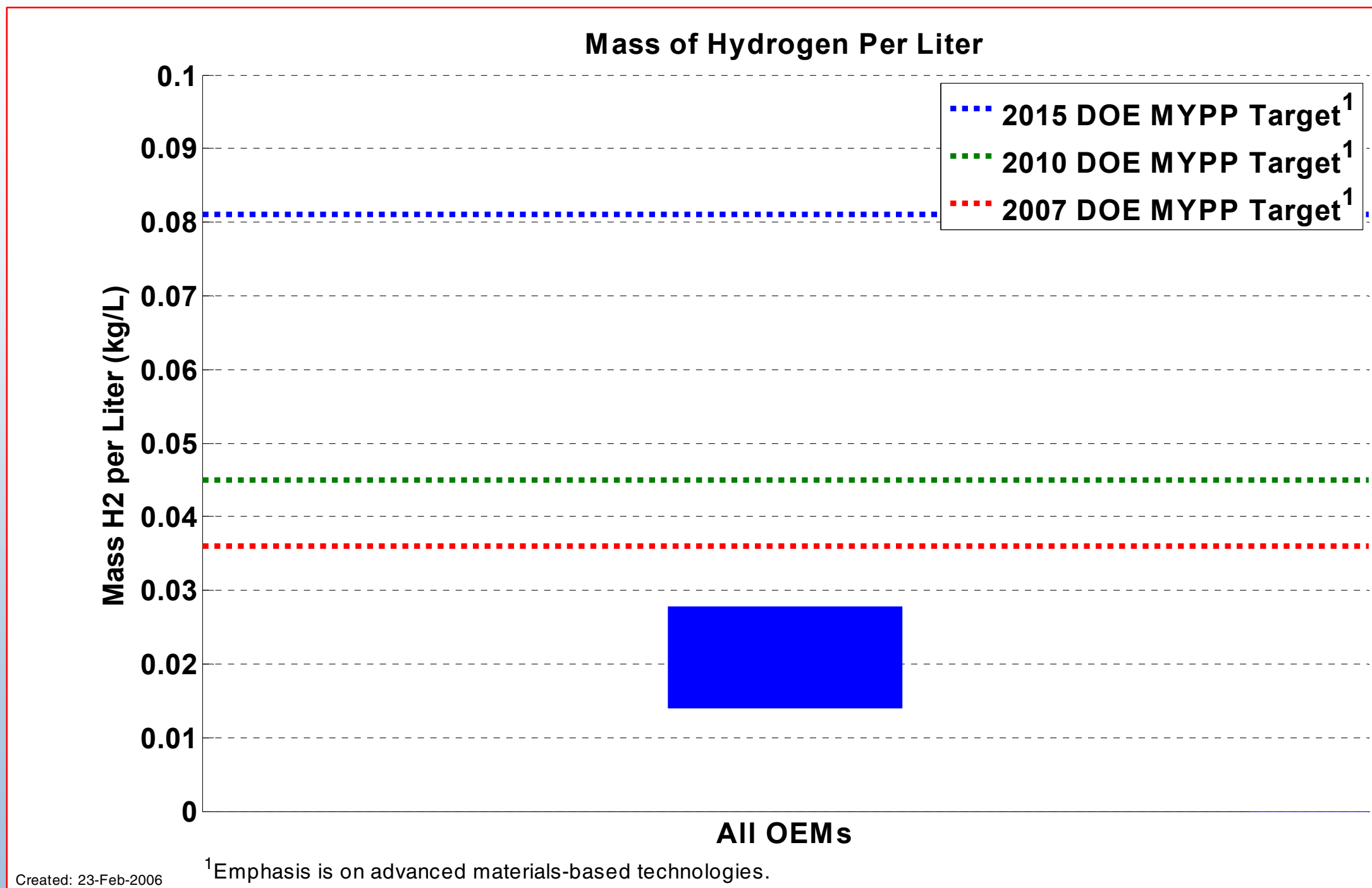




\section{CDP\#12: Vehicle Hydrogen Tank Cycle Life}

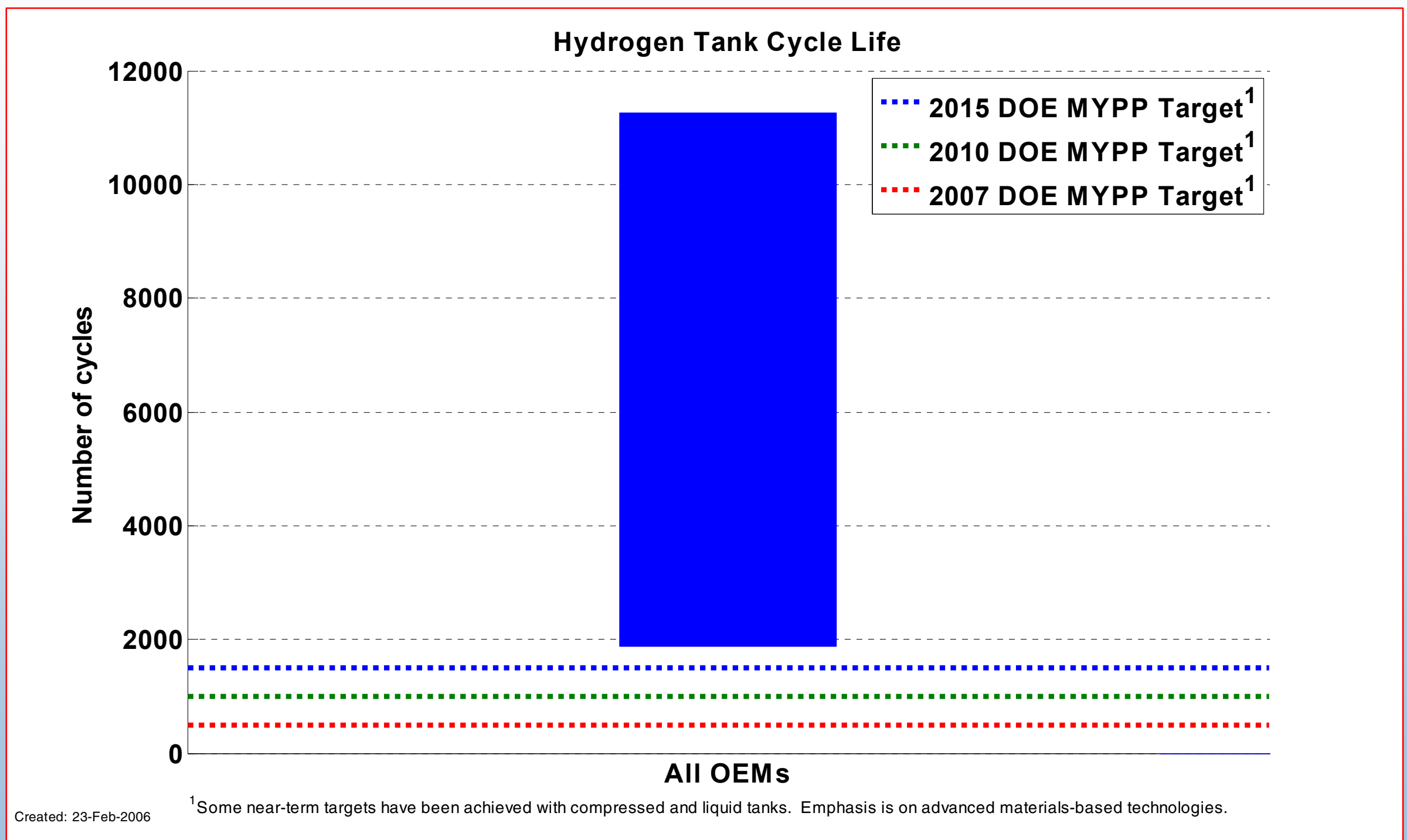




\section{CDP\#18: Histogram: Refueling Rate}

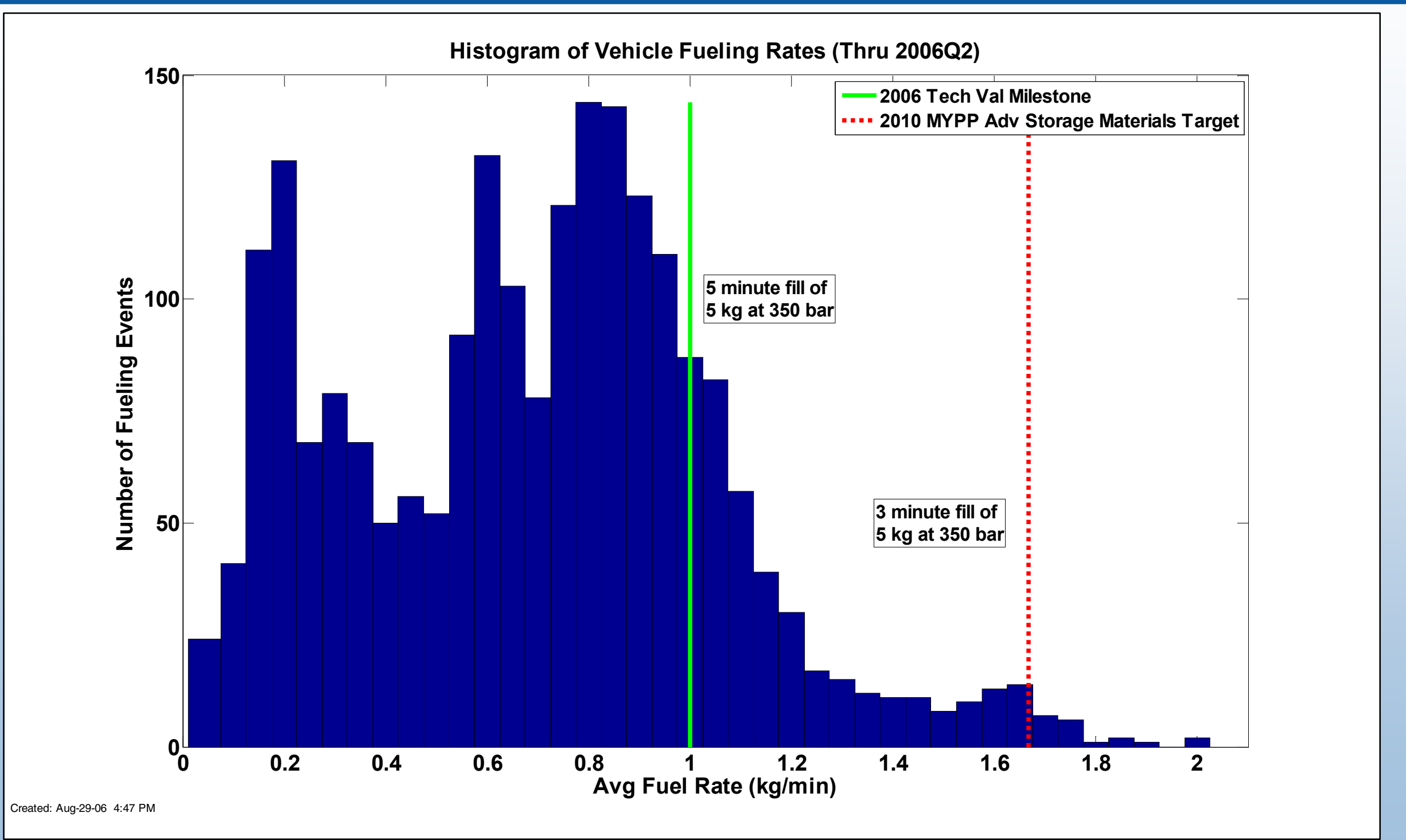




\section{CDP\#20: Safety Incidents - Infrastructure}

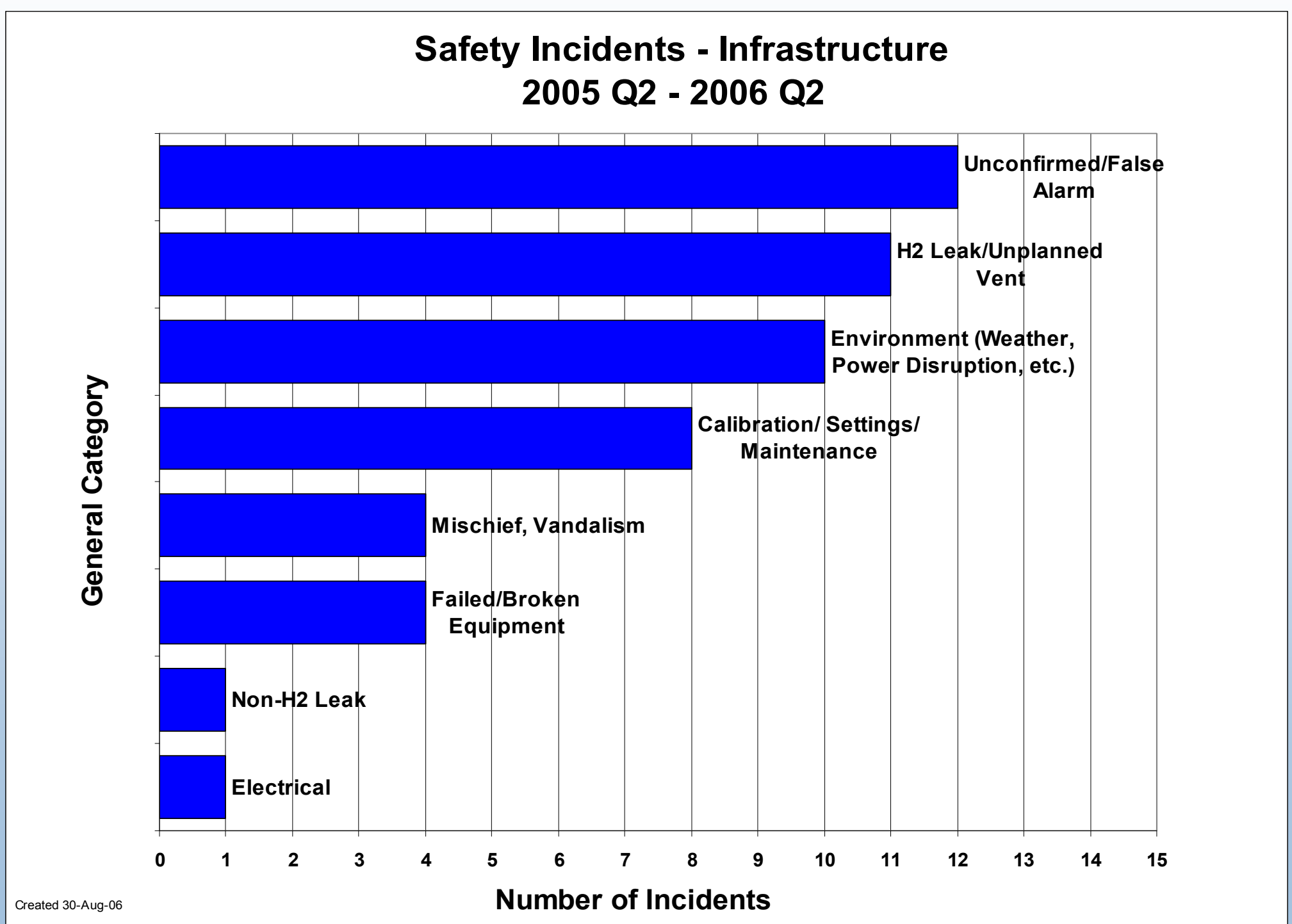




\section{CDP\#21: Range of Ambient Temperature During Vehicle Operation}

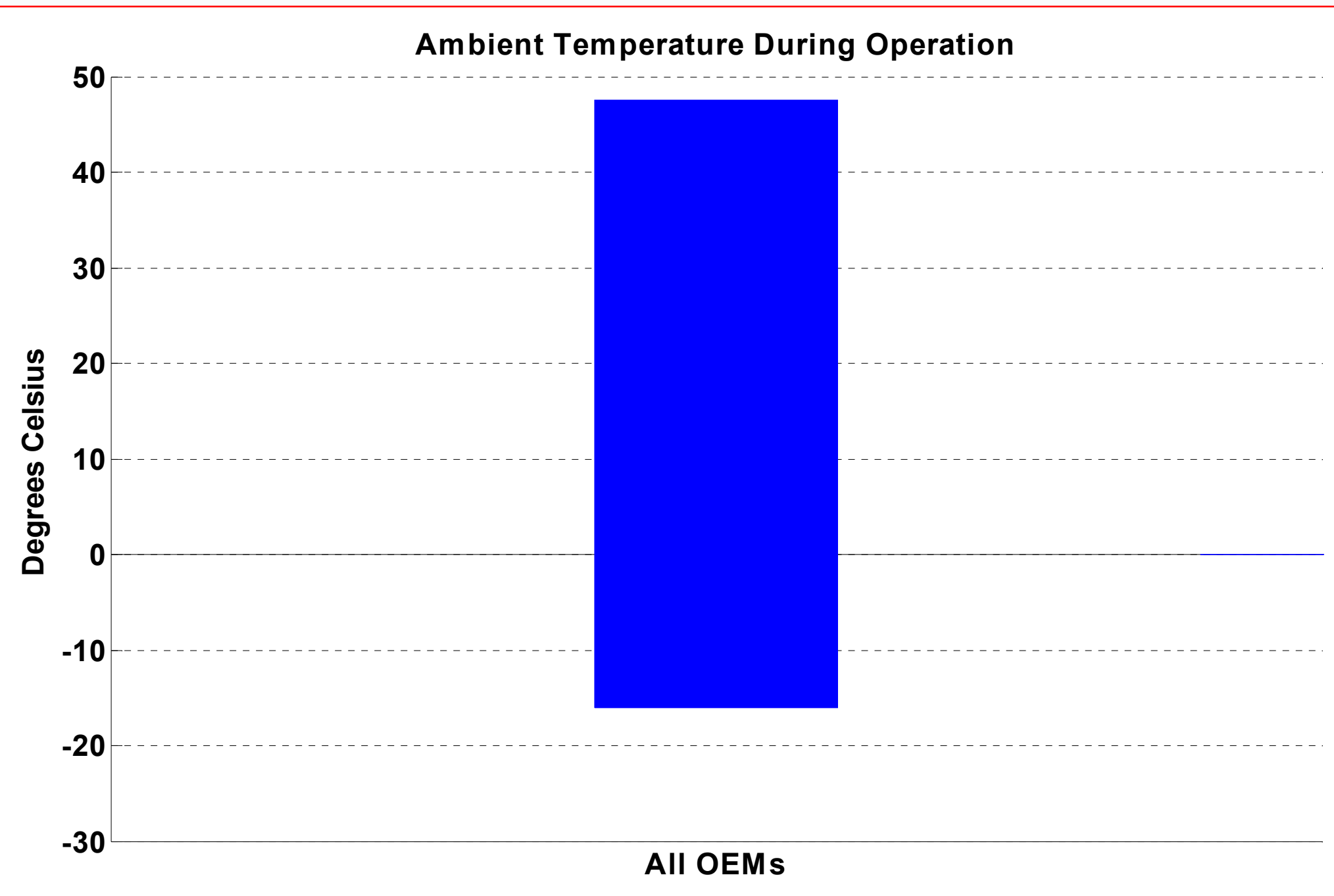




\section{CDP\#22: Vehicle Operating Hours}

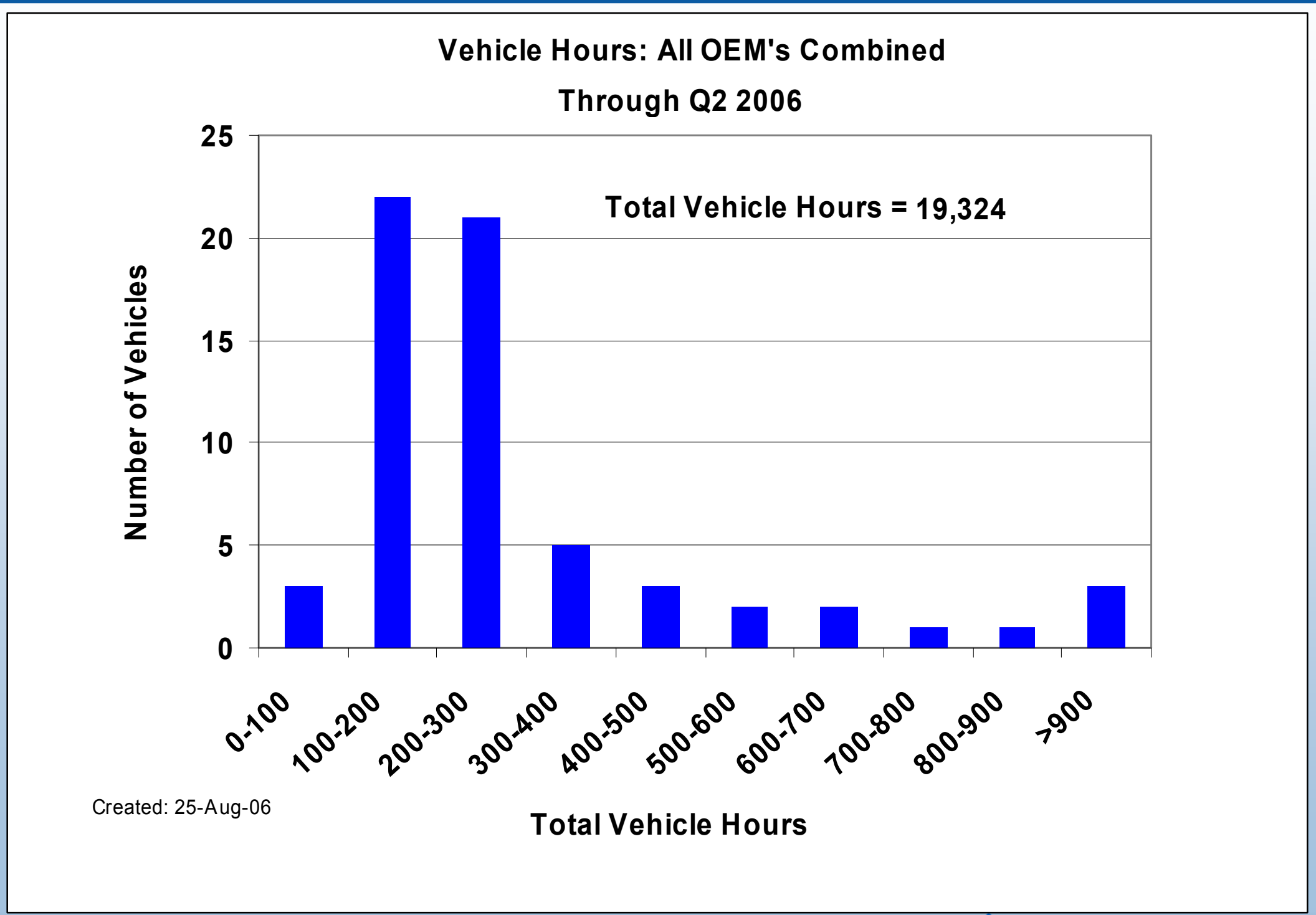




\section{CDP\#23: Vehicles vs. Miles Traveled}

Vehicle Miles: All OEMs Combined

Through Q2 2006

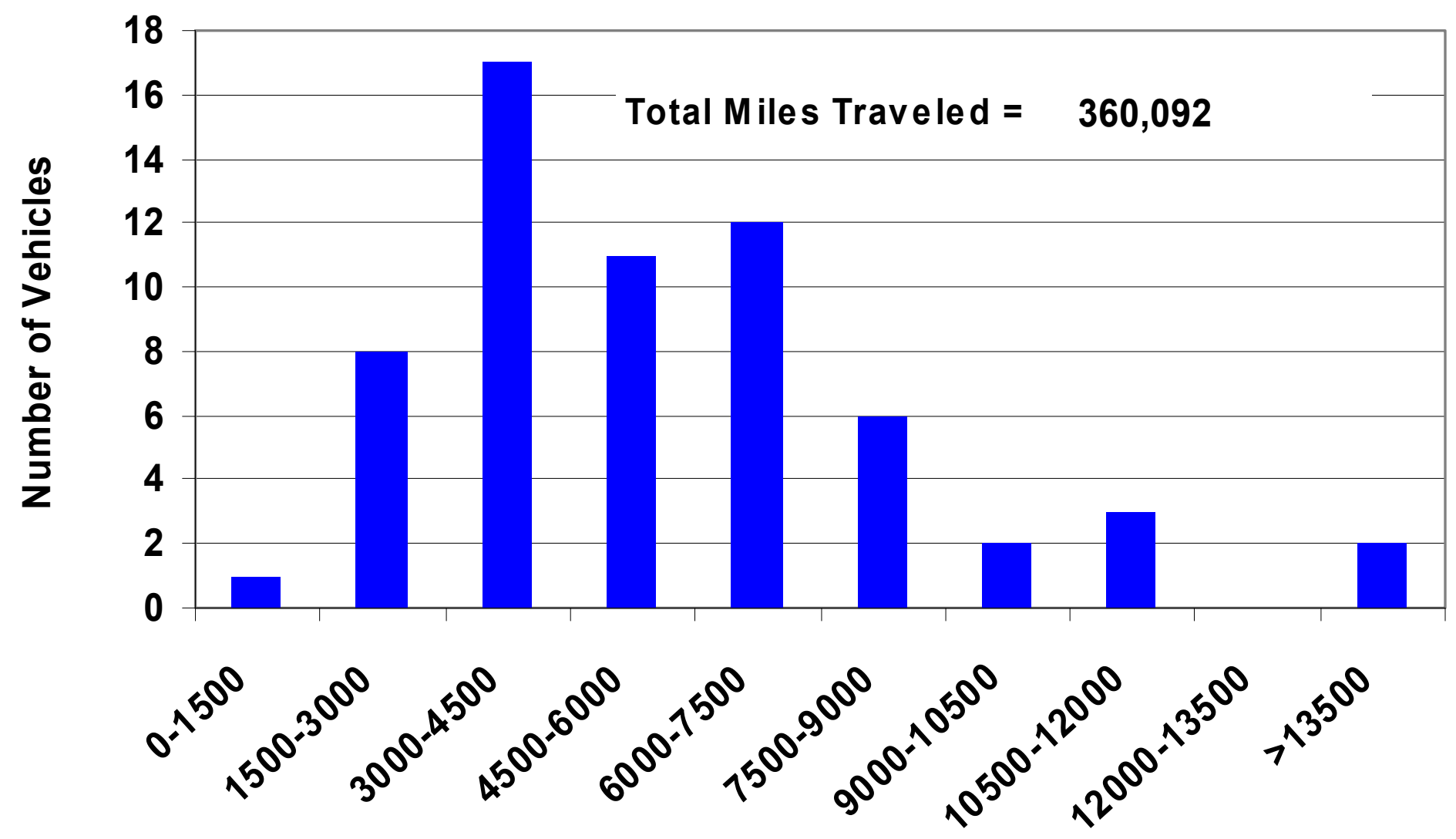

Total Vehicle Miles 


\section{CDP\#24: Cumulative Vehicle Miles Traveled}

Cumulative Vehicle Miles Traveled: All OEMs

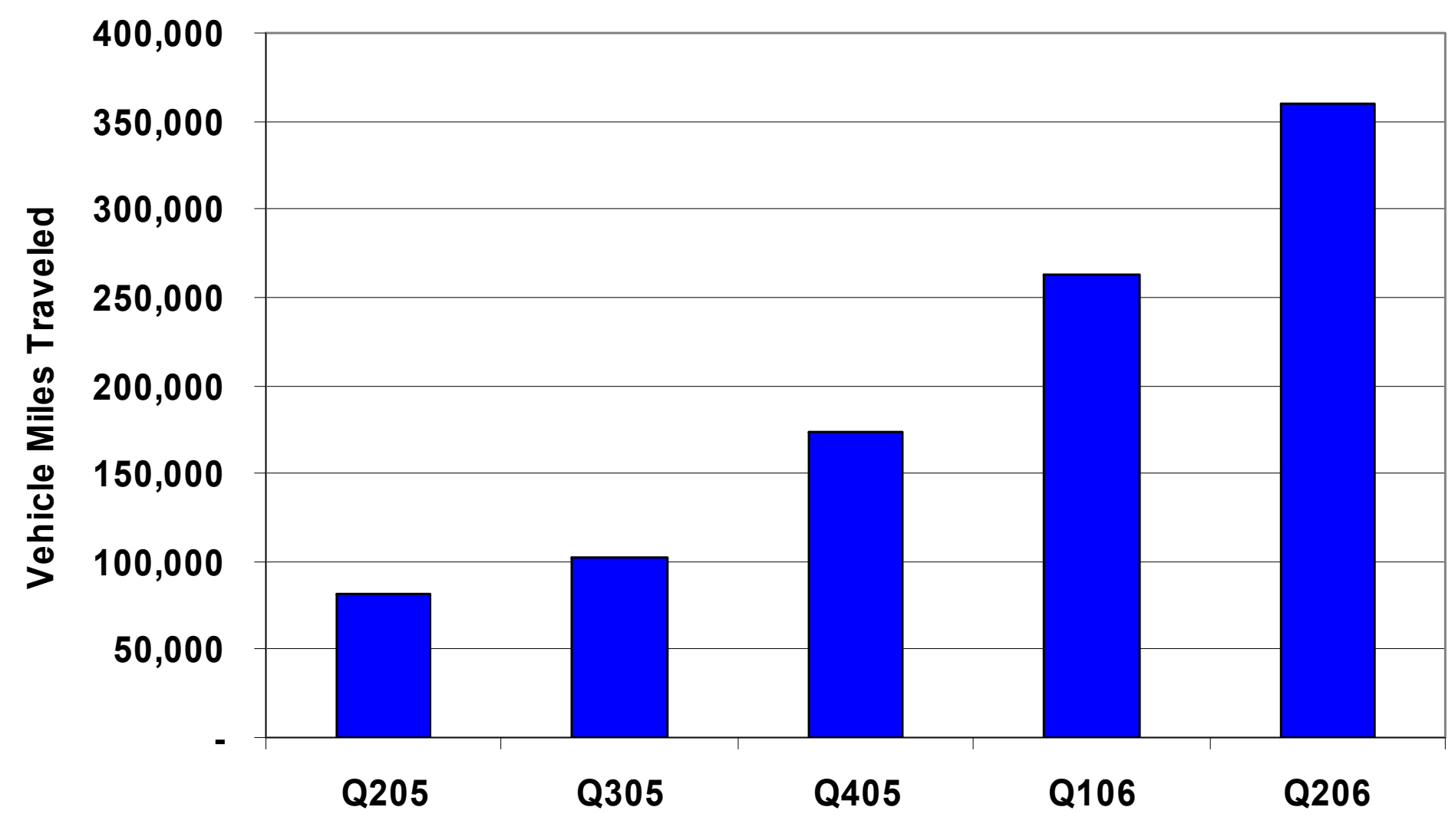

Created: 28-Aug-06 


\section{CDP\#25: Vehicle H2 Storage Technologies}

On-Board Hydrogen Storage Methods

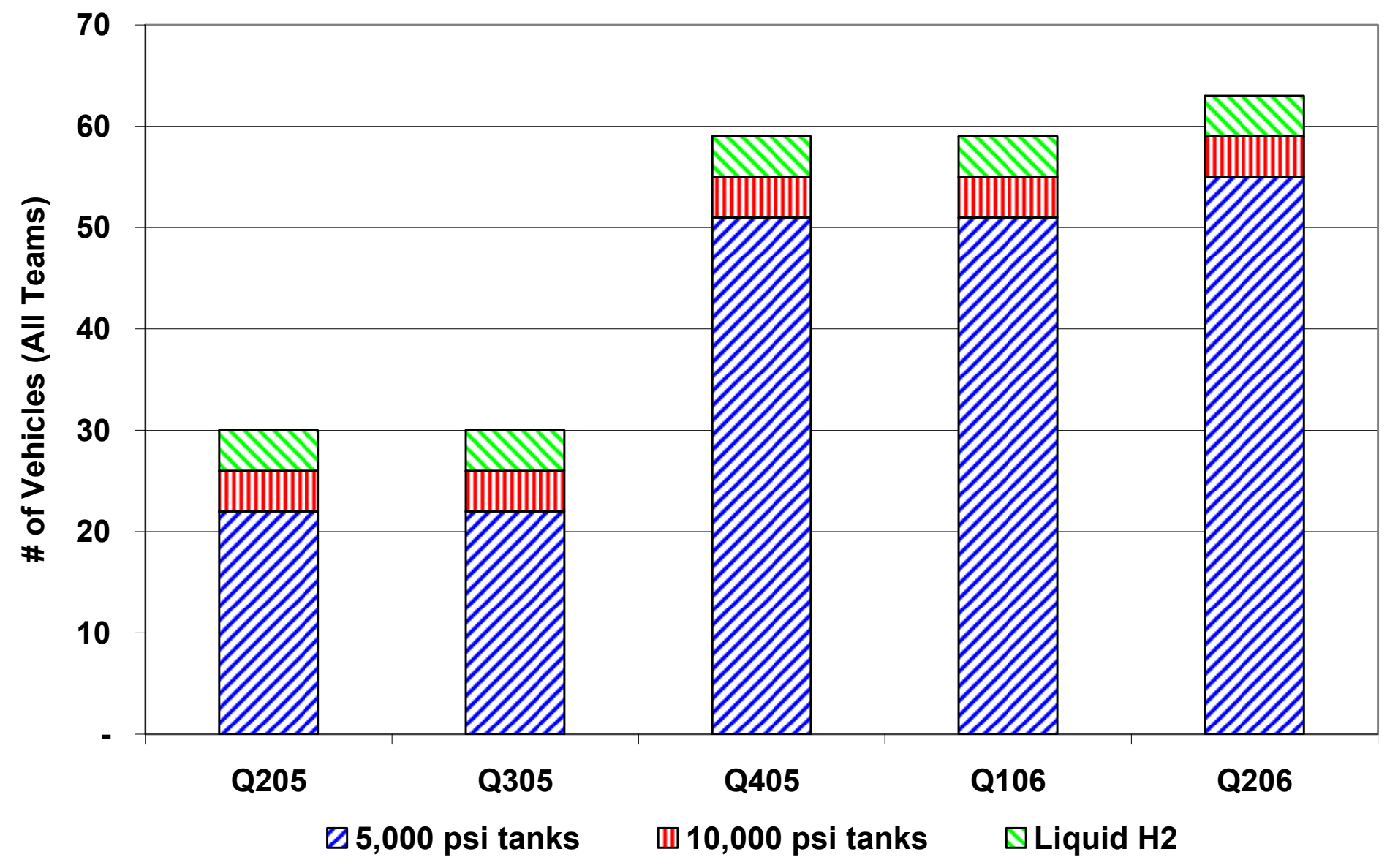




\section{CDP\#26: Cumulative H2 Produced or Dispensed}

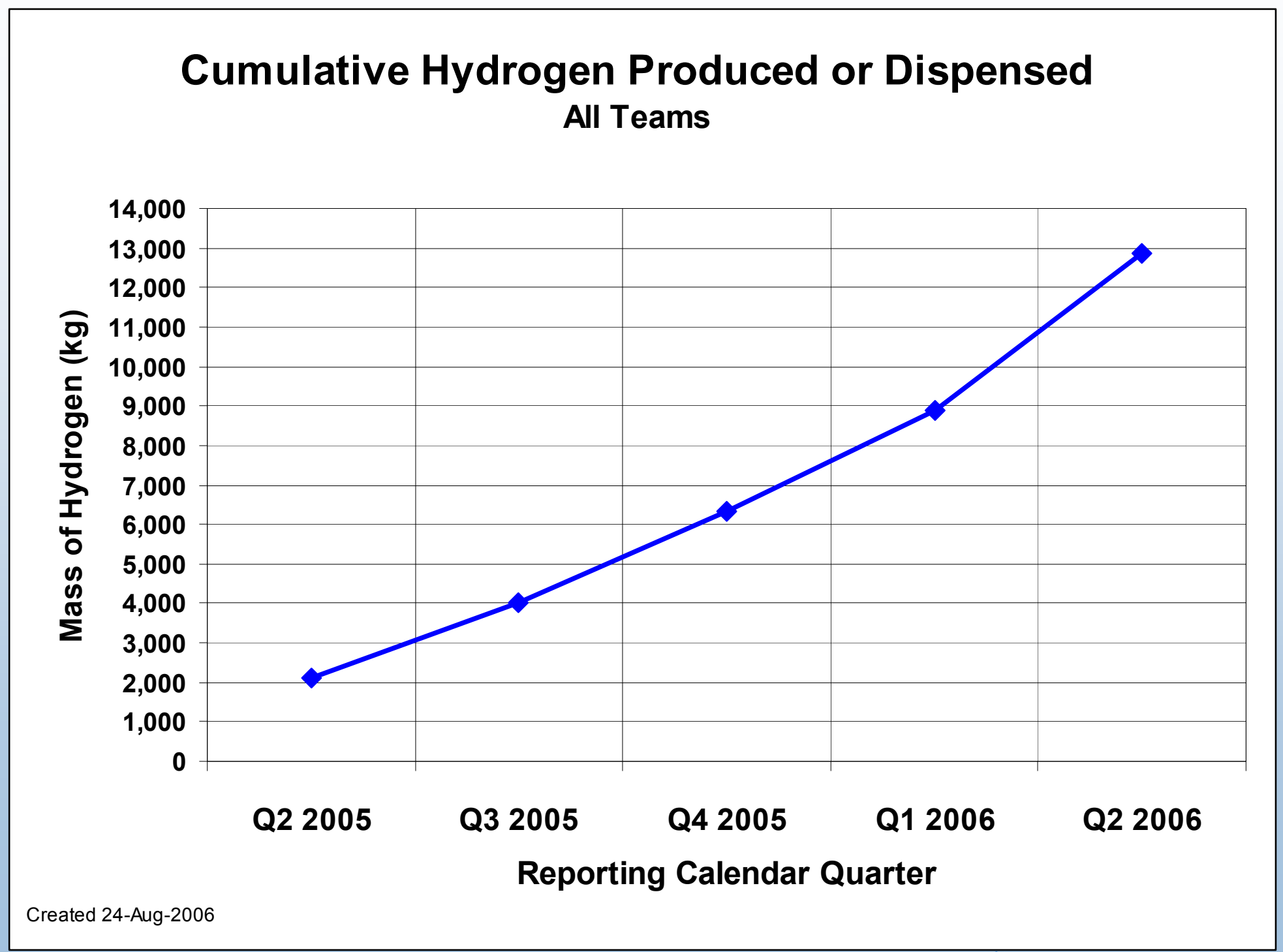




\section{CDP \#28: Hydrogen Impurities Scatter Plot}

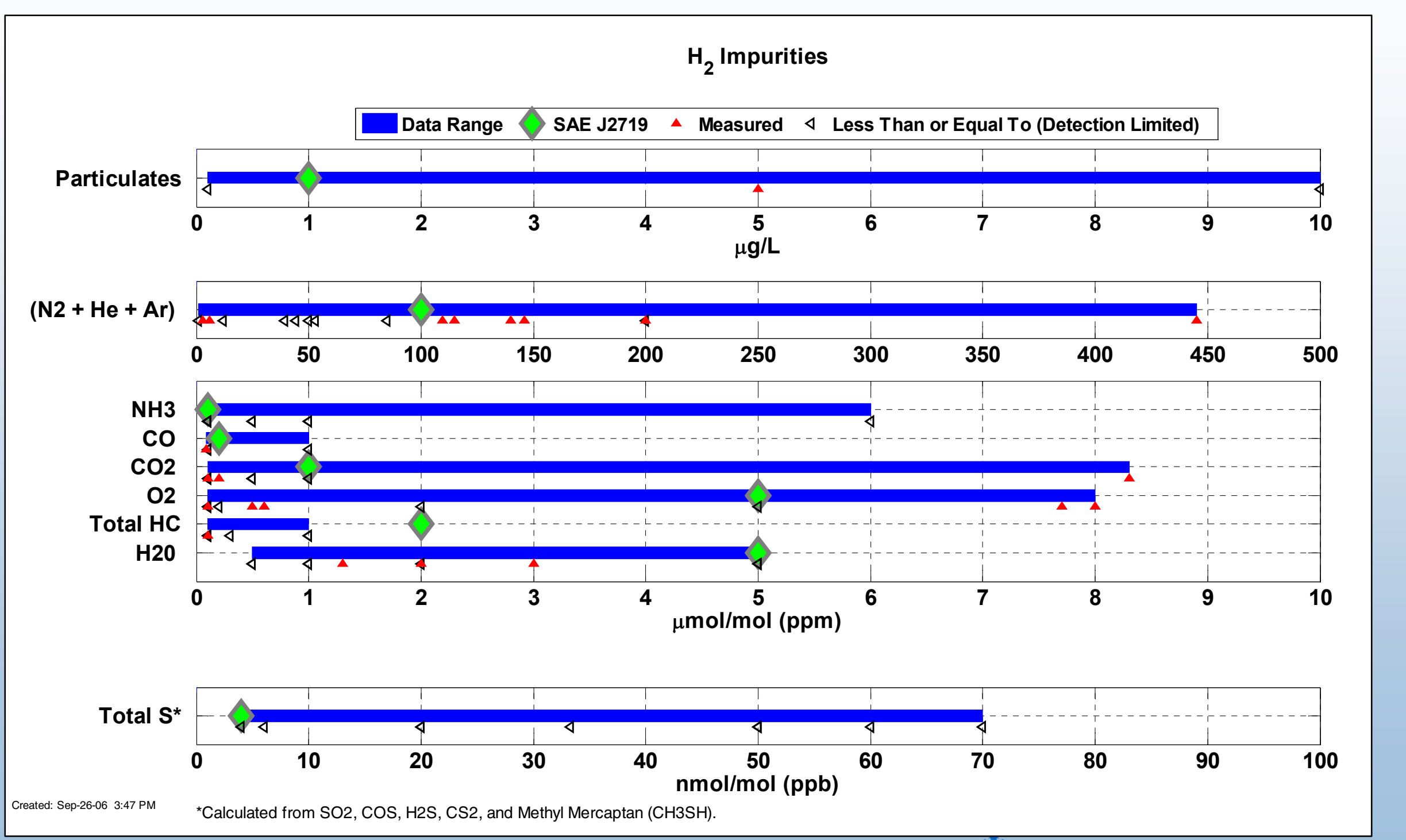




\section{CDP\#30: Infrastructure Maintenance}

Maintenance: Average Labor Hours Per Station Since Inception

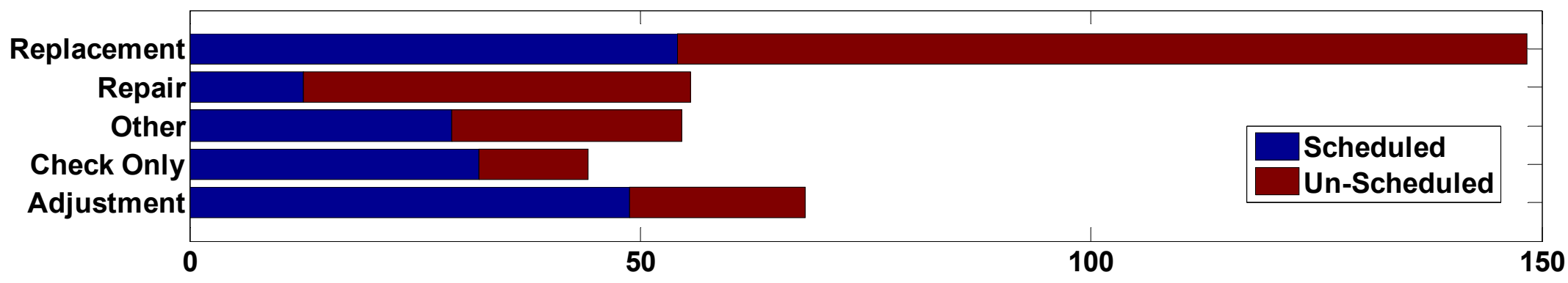

Maintenance: Average Number of Events Per Station Since Inception

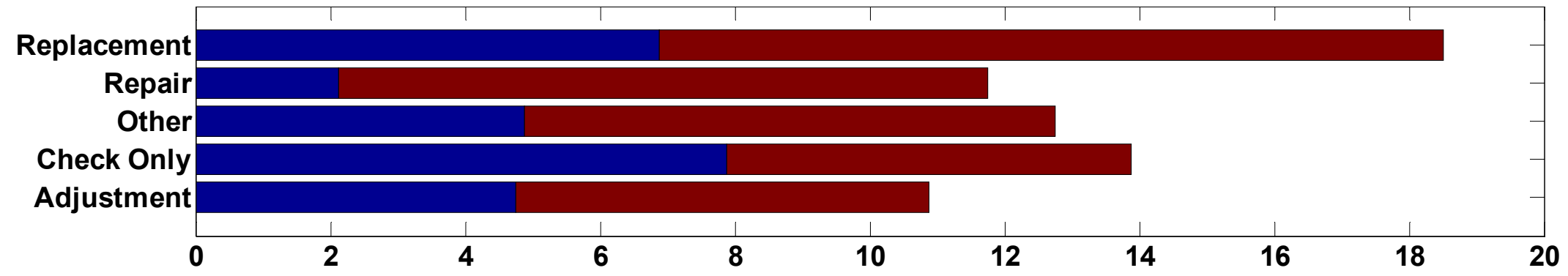

Comparison of Scheduled/Un-Scheduled Maintenance

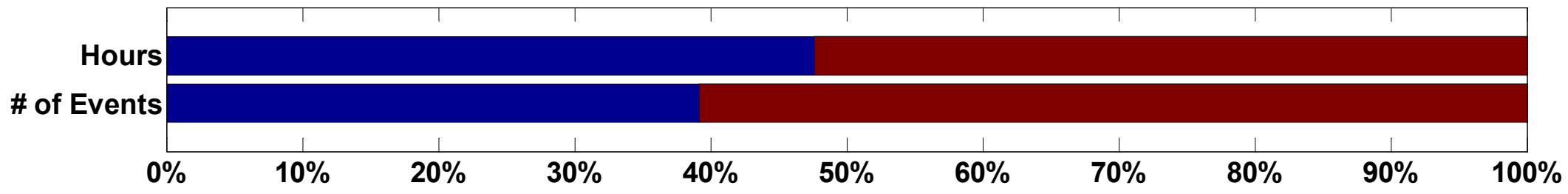




\section{CDP\#31: Number of Reporting Stations}

\section{Number of Stations}

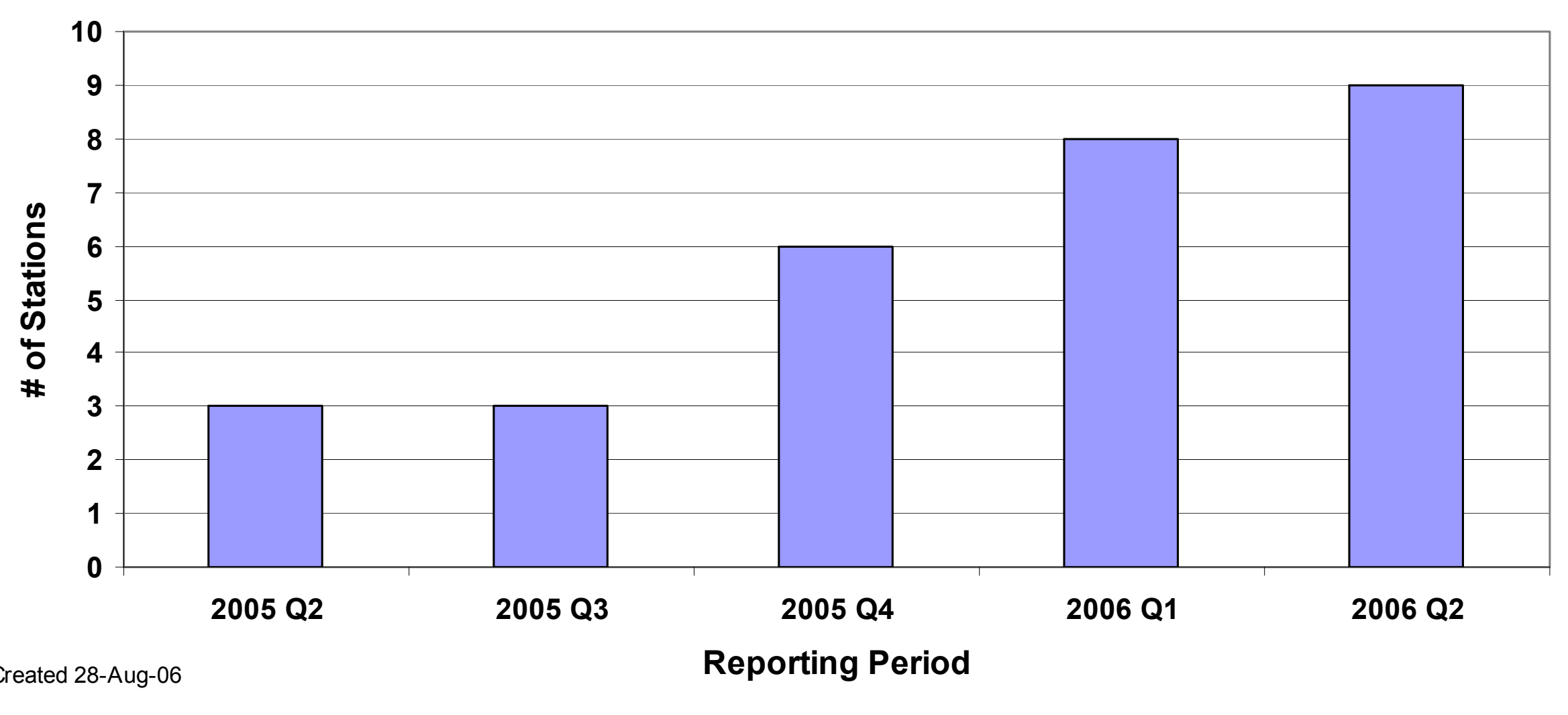




\section{CDP\#32: Hydrogen Production Methods}

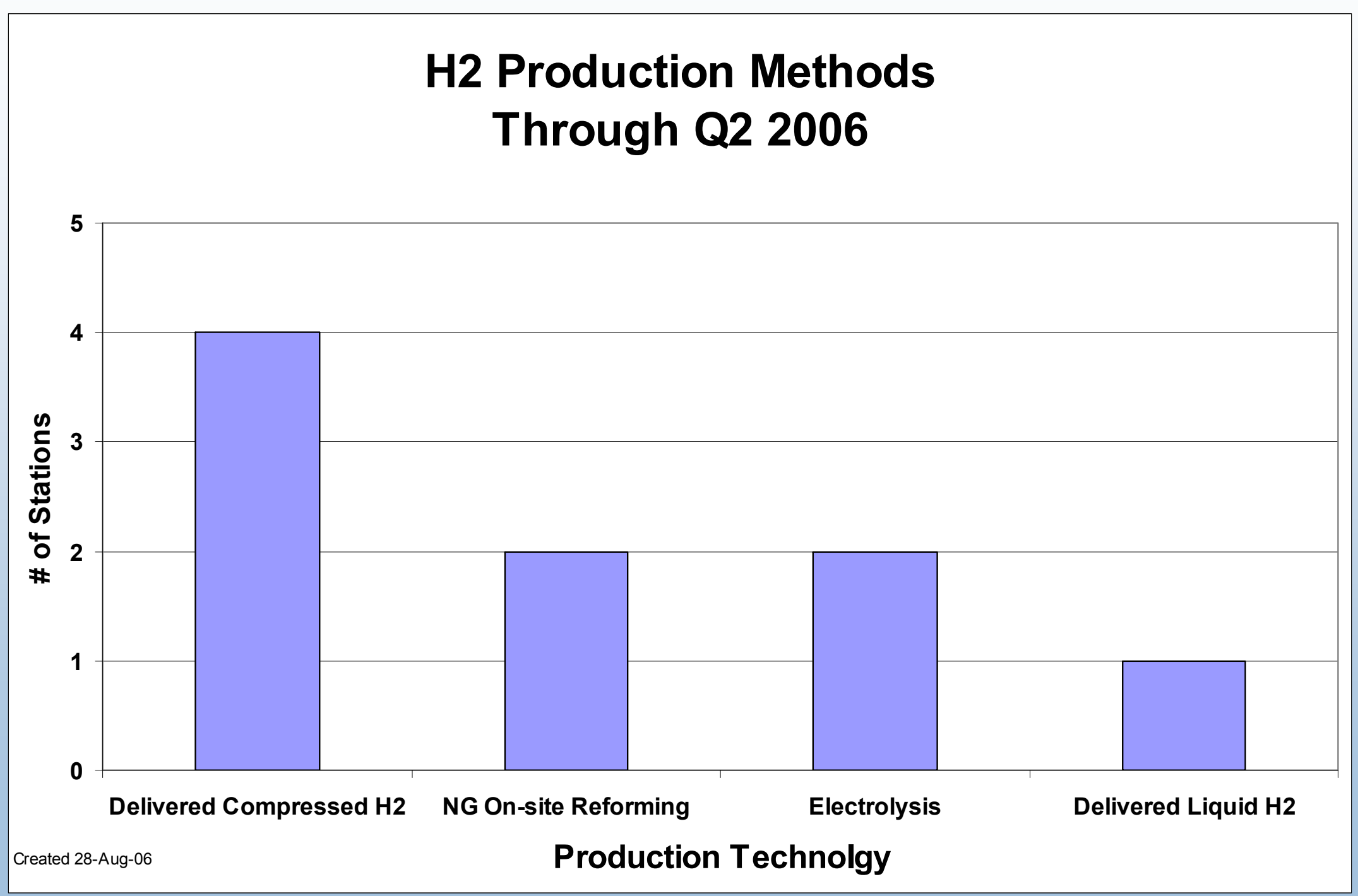




\section{CDP\#33: Percentage of Theoretical Range Between Refuelings}

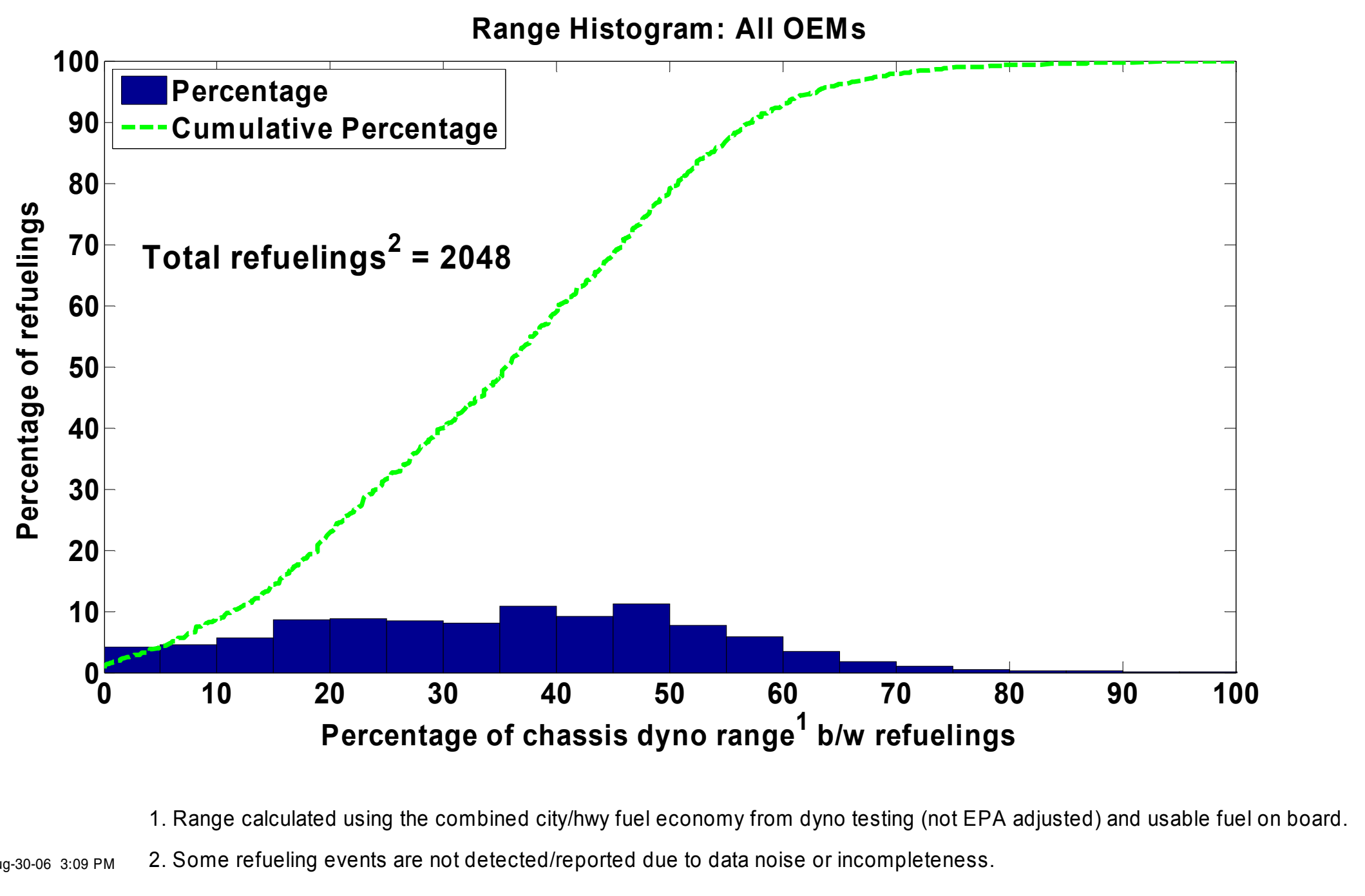

2. Some refueling events are not detected/reported due to data noise or incompleteness. 


\section{CDP\#34: Effective Vehicle Range}

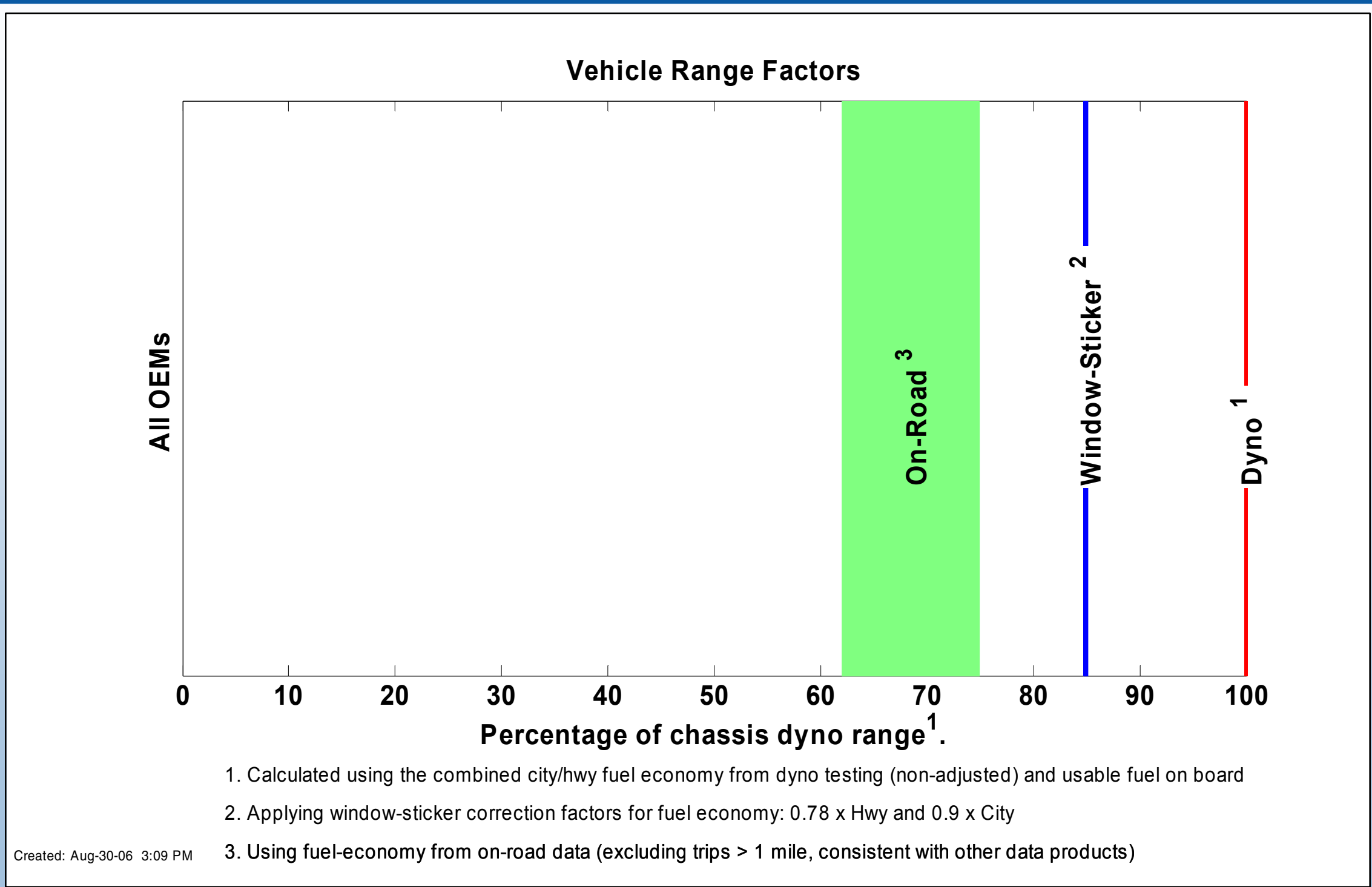




\section{REPORT DOCUMENTATION PAGE}

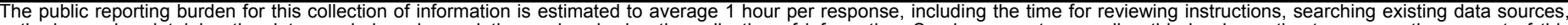

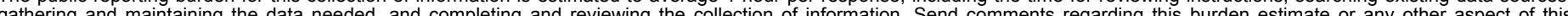

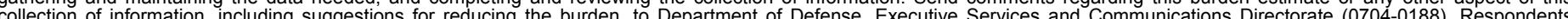

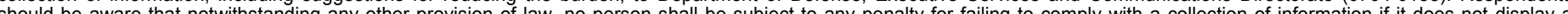

should be awaris

PLEASE DO NOT RETURN YOUR FORM TO THE ABOVE ORGANIZATION.

Completed Learning Demonstration Composite Data Products as of
1. REPORT DATE (DD-MM-YYYY)
February 2007

\section{REPORT TYPE \\ Technical Report}

4. TITLE AND SUBTITLE

12/01/06
3. DATES COVERED (From - To) 4/06 - 10/06

5a. CONTRACT NUMBER

DE-AC36-99-G010337

5b. GRANT NUMBER

5c. PROGRAM ELEMENT NUMBER

5d. PROJECT NUMBER

NREL/TP-560-41090

5e. TASK NUMBER

$\mathrm{H} 270-8100$

5f. WORK UNIT NUMBER
7. PERFORMING ORGANIZATION NAME(S) AND ADDRESS(ES)

National Renewable Energy Laboratory

1617 Cole Blvd.

Golden, CO 80401-3393
8. PERFORMING ORGANIZATION REPORT NUMBER

NREL/TP-560-41090

9. SPONSORING/MONITORING AGENCY NAME(S) AND ADDRESS(ES)

10. SPONSOR/MONITOR'S ACRONYM(S) NREL

11. SPONSORING/MONITORING AGENCY REPORT NUMBER

12. DISTRIBUTION AVAILABILITY STATEMENT

National Technical Information Service

U.S. Department of Commerce

5285 Port Royal Road

Springfield, VA 22161

13. SUPPLEMENTARY NOTES

14. ABSTRACT (Maximum 200 Words)

These public technical analysis results from DOE's Controlled Hydrogen Fleet and Infrastructure Demonstration and

Validation Project are generated in the form of composite data products.

\section{SUBJECT TERMS}

composite data products; technology validation; Controlled Hydrogen Fleet and Infrastructure Demonstration and Validation Project; learning demonstration

\begin{tabular}{|c|c|c|c|c|}
\hline 16. SECURITY & CLASSIFICATI & N OF: & 17. LIMITATION & 18. NUMBER \\
\hline $\begin{array}{l}\text { a. REPORT } \\
\text { Unclassified }\end{array}$ & $\begin{array}{l}\text { b. ABSTRACT } \\
\text { Unclassified }\end{array}$ & $\begin{array}{l}\text { c. THIS PAGE } \\
\text { Unclassified }\end{array}$ & UL & \\
\hline
\end{tabular}

19a. NAME OF RESPONSIBLE PERSON

19b. TELEPHONE NUMBER (Include area code) 